\title{
Clinical Study \\ Heart Rate and Arterial Pressure Changes during Whole-Body Deep Hypothermia
}

\author{
Giacomo Cavallaro, ${ }^{1}$ Luca Filippi, ${ }^{2}$ Genny Raffaeli, ${ }^{1}$ Gloria Cristofori, ${ }^{1}$ \\ Federico Schena, ${ }^{1}$ Elisa Agazzani, ${ }^{3}$ Ilaria Amodeo, ${ }^{1}$ Alice Griggio, ${ }^{1}$ \\ Simona Boccacci, ${ }^{3}$ Patrizio Fiorini, ${ }^{2}$ and Fabio Mosca ${ }^{1}$ \\ ${ }^{1}$ NICU, Fondazione IRCCS Cà Granda, Ospedale Maggiore Policlinico, Università degli Studi di Milano, \\ Via Della Commenda 12, 20122 Milan, Italy \\ ${ }^{2}$ NICU, Medical Surgical Feto-Neonatal Department, "A. Meyer" University Children's Hospital, Viale G. Pieraccini, \\ 24, 50139 Florence, Italy \\ ${ }^{3}$ Neonatal Intensive Care Unit, "Carlo Poma" Hospital, Mantova, Italy
}

Correspondence should be addressed to Giacomo Cavallaro; giacomo.cavallaro@mangiagalli.it

Received 31 January 2013; Accepted 18 March 2013

Academic Editors: A. Maheshwari and B. Vasarhelyi

Copyright (C) 2013 Giacomo Cavallaro et al. This is an open access article distributed under the Creative Commons Attribution License, which permits unrestricted use, distribution, and reproduction in any medium, provided the original work is properly cited.

\begin{abstract}
Whole-body deep hypothermia (DH) could be a new therapeutic strategy for asphyxiated newborn. This retrospective study describes how DH modified the heart rate and arterial blood pressure if compared to mild hypothermia $(\mathrm{MH})$. Fourteen in $\mathrm{DH}$ and 17 in $\mathrm{MH}$ were cooled within the first six hours of life and for the following 72 hours. Hypothermia criteria were gestational age $\geq 36$ weeks; birth weight $\geq 1800 \mathrm{~g}$; clinical signs of moderate/severe hypoxic-ischemic encephalopathy. Rewarming was obtained in the following 6-12 hours $\left(0.5^{\circ} \mathrm{C} / \mathrm{h}\right)$ after cooling. Heart rates were the same between the two groups; there was statistically significant difference at the beginning of hypothermia and during rewarming. Three babies in the DH group and 2 in the MH group showed $\mathrm{HR}<80 \mathrm{bpm}$ and QTc $>520 \mathrm{~ms}$. Infant submitted to deep hypothermia had not bradycardia or Qtc elongation before cooling and after rewarming. Blood pressure was significantly lower in $\mathrm{DH}$ compared to $\mathrm{MH}$ during the cooling, and peculiar was the hypotension during rewarming in DH group. Conclusion. The deeper hypothermia is a safe and feasible, only if it is performed by a well-trained team. DH should only be associated with a clinical trial and prospective randomized trials to validate its use.
\end{abstract}

\section{Introduction}

Hypoxic-ischemic encephalopathy (HIE) is a disease that induces death and severe neurological damage in newborns [1]. Hypothermia is now the first effective neuroprotective intervention for newborns that are critically ill following an asphyxial insult. Hypothermia showed a decrease in death or disability at 18 months [2-5]. Parkins et al. firstly introduced hypothermia as a neuroprotective method, but the side effects were higher, so the practice had been abandoned [6]. Metaanalysis about eight largest RCTs had confirmed that cooling reduced mortality without increasing handicap in survivors [7]. Two meta-analyses have confirmed that hypothermia was associated with a lower risk of death or moderate/severe neurodevelopmental disorder in childhood, but with an increased risk of arrhythmia and thrombocytopenia $[8,9]$. Perlman suggested that deeper or more prolonged cooling could be able to treat more severe neonatal asphyxia [2] The early studies of deep hypothermia $\left(20-27^{\circ} \mathrm{C}\right)$ have found some neurological benefits, but the side effects dramatically increased below $32^{\circ} \mathrm{C}$ and passed all potential clinical benefits [10]. Shivering and cardiac arrhythmias were the most pronounced of these side effects $[11,12]$. Cardiac arrhythmias, hypotension, hemoconcentration, sinus bradycardia, and peripheral vasoconstriction are common adverse events in neonatal hypothermia [13-15]. Safety and respiratory function during deep hypothermia (DH) in asphyxiated newborn were previously reported [16, 17]. Retrospective analysis of circulatory parameters is part of a prospective study designed to investigate the safety of the topiramate $[18,19]$. 
The objective of this retrospective analysis was to investigate how heart rate and systemic arterial pressure were modified by $\mathrm{DH}$ (core temperature $30-33^{\circ} \mathrm{C}$ ). Results were compared to a group of term infants with hypoxic-ischemic encephalopathy (HIE) treated with milder levels of hypothermia $(\mathrm{MH})$ (core temperature $33-34^{\circ} \mathrm{C}$ ).

\section{Methods}

Asphyxiated newborns included in the analysis were those treated with whole-body $\mathrm{DH}$ or $\mathrm{MH}$ within the first 6 hours of life and if the two following criteria were fulfilled: (1) gestational age $\geq 36$ weeks and birth weight $\geq 1.800 \mathrm{~g}$, with at least one of the following: (a) Apgar score $\leq 5$ at 10 minutes; (b) endotracheal intubation or mask ventilation for more than 10 minutes after birth; (c) acidosis $(\mathrm{pH} \leq 7.0$ and/or basic excess $\geq-16 \mathrm{mmol} / \mathrm{L}$ in umbilical cord blood or arterial, venous, or capillary blood) within 60 minutes from birth; (2) moderate to severe encephalopathy consisting of altered state of consciousness (irritability, lethargy, stupor, or coma) and $\geq 1$ of the following signs: (a) hypotonia, (b) abnormal reflexes, including oculomotor or pupillary abnormalities, (c) absent or weak suctioning, and (d) clinical seizures $[3,10]$. Between November 2004 and May 2010, 78 asphyxiated newborns with HIE were retrospectively compared: 37 patients were treated with $\mathrm{DH}$ and 41 with $\mathrm{MH}$. Four patients in each group were excluded because they were cooled with ice packs. Nineteen patients in $\mathrm{DH}$ and 20 patients in $\mathrm{MH}$ were excluded because they received inotropic supply. Fourteen patients in $\mathrm{DH}$ and 17 in $\mathrm{MH}$ were analyzed.

Patients were cooled by two different cooling blankets, NIG 2 (Iemmi Medical Srl.; Mantova, Italy) and Blanketrol III (Hyper-Hypothermia System, Cincinnati Sub-Zero, Cincinnati, $\mathrm{OH}, \mathrm{USA})$. Monitoring was performed by a rectal and esophageal probe. Skin temperature was monitored on the abdominal wall with a skin probe by the radiant warmer thermal sensor or a temperature-monitoring unit (Mon-atherm; Mallinckrodt Medical, St. Louis, MO, USA). The target of the core temperature was $31^{\circ} \mathrm{C}$ and $33.5^{\circ} \mathrm{C}$ for $\mathrm{DH}$ and $\mathrm{MH}$, respectively. Cooling was maintained between the stated targets for $72 \mathrm{~h}$, and rewarming to $36.5-37^{\circ} \mathrm{C}$ was gradually obtained over the following $6-12 \mathrm{~h}\left(0.5^{\circ} \mathrm{C} / \mathrm{h}\right)$.

Arterial blood gas, coagulation, and biochemistry were daily checked and temperature corrected. Chest $\mathrm{X}$ rays and echocardiography (Acuson Sequoia C512, Siemens, Germany) were performed at the admission. The scans were performed by 2 experienced operators. Respiratory rate, heart rate (HR), blood pressure (BP), and oxygen saturation were continuously monitored during hypothermia and rewarming. BP was measured by using standard oscillometric methods. Invasive blood pressure monitoring was not performed routinely. Only oscillometric blood pressure values were selected for analysis to reduce the bias. Standard electrocardiogram was obtained when bradycardia (HR of $<80$ bpm) or arrhythmia (extrasystoles, bundle branch block) was observed. Hypotension, defined as mean arterial blood pressure (MAP) $<40 \mathrm{~mm} \mathrm{Hg}$, was, firstly, treated with single or repeated normal saline boluses $(10-20 \mathrm{~mL} / \mathrm{kg})$ and subsequently by dopamine, while dobutamine was infused when the reduction of myocardial contractility was found. Dopamine or dobutamine was started at an initial dose of $5 \mathrm{ug} / \mathrm{kg} / \mathrm{min}$ and was increased by $5 \mathrm{ug} / \mathrm{kg} / \mathrm{min}$ up to a maximum dose of $15 \mathrm{ug} / \mathrm{kg} / \mathrm{min}$. Fluid intake was started at 60 to $70 \mathrm{~mL} / \mathrm{kg}$ and increased by 10 to $20 \mathrm{~mL} / \mathrm{kg}$ each day, based on changes in body weight and serum electrolyte levels. Clinical seizures were treated with phenobarbital (loading dose, $20 \mathrm{mg} / \mathrm{kg}$; followed by $1.5-2.5 \mathrm{mg} / \mathrm{kg}$ every 12 hours). Oral topiramate was administered as neuroprotective drug at starting time of hypothermia, once a day for 3 days $[18,19]$. Inhaled nitric oxide was started when PPHN was echographically demonstrated.

Brain magnetic resonance imaging (MRI) was planned within the first week of life. Brain lesions were classified as isolated lesions of white matter, basal ganglia, and thalamus with or without involvement of posterior limb of the internal capsule, cortex, or various combinations of the earlier lesions [20].

\section{Statistical Analyses}

Results were shown as mean \pm SD or percentage. Statistical analyses were performed using Student's $t$-test, MannWhitney test, and ANOVA; categorical variables were analyzed using Fisher exact test or $\chi^{2}$ analyses. A paired $t$-test was used to determine the effect of a single treatment. $P$ value of $\leq 0.05$ was considered significant.

\section{Results}

Newborns reported in three earlier study were included [1719]. Seventy-eight asphyxiated newborns were retrospectively compared from November 2004 to May 2010: 37 patients were treated with $\mathrm{DH}$, and 41 with $\mathrm{MH}$. Four patients in both groups were excluded because they were cooled with ice packs. Nineteen patients in $\mathrm{DH}$ and 20 patients in $\mathrm{MH}$ were excluded because they received inotropic supply. Fourteen patients in $\mathrm{DH}$ and 17 in $\mathrm{MH}$ were analyzed, and there was not a statistically significant difference between the two groups $(P=0.855)$. Perinatal and basic characteristics of the infants were not significantly different (Table 1). Core temperatures were the same between the two groups at hypothermic starting time. During treatment, the core temperature was, respectively, maintained at $31^{\circ} \mathrm{C}$ and $33.5^{\circ} \mathrm{C}$ in $\mathrm{DH}$ and $\mathrm{MH}$. There was a statistical significant difference $(P<0.001)$ from 6 to 72 hours between the two groups (Figure 1). At starting cooling, mean HR was $110 \mathrm{bpm}$ and $111 \mathrm{bpm}$ during $\mathrm{DH}$ and $\mathrm{MH}$, whereas it was reduced at $97 \mathrm{bpm}$ and $105 \mathrm{bpm}$ during $\mathrm{DH}$ and $\mathrm{MH}$ (Figure 2). Three babies in $\mathrm{DH}(20 \%)$ and 2 in $\mathrm{MH}(11.7 \%)$ showed a sinus bradycardia (HR $<80 \mathrm{bpm}$ ), with a significant increase in QTc (>520 ms) during hypothermia $(P=0.326)$. Newborns did not have bradycardia before cooling and after rewarming. Heart rate decreased significantly by a mean of $11 \mathrm{bpm}$ in $\mathrm{DH}$ and nine bpm in MH on cooling (Figure 2). Sinus bradycardia was not associated with a decrease of mean arterial pressure (MAP), and arrhythmia has not been reported. Mean systolic arterial 
TABLE 1: Basic characteristics of the group. (mean \pm SD or $n$ and \%).

\begin{tabular}{|c|c|c|c|c|}
\hline & $\begin{array}{c}\text { Group DH } \\
n=14 / 31(45.1)\end{array}$ & $\begin{array}{c}\text { Group MH } \\
n=17 / 31(54.9)\end{array}$ & $P$ value & 95\% C.I. \\
\hline Weight g (SD) & $3296( \pm 659)$ & $3292( \pm 608)$ & $P=0.982$ & $-299.0-305.7$ \\
\hline Gestational age weeks (SD) & $39.6( \pm 1.7)$ & $39.2( \pm 1.9)$ & $P=0.488$ & $-0.737-1.222$ \\
\hline Inborn $n(\%)$ & $5 / 14(35.7)$ & $7 / 17(23.5)$ & $P=0.738$ & $-0.482-0.726$ \\
\hline Male $n(\%)$ & $6 / 14(42.8)$ & $12 / 17(70.5)$ & $P=0.533$ & $-0.754-0.200$ \\
\hline Caucasian race $n(\%)$ & $11 / 14(78.5)$ & $13 / 17(76.4)$ & $P=0.714$ & $-0.315-0.357$ \\
\hline Vaginal delivery $n(\%)$ & $6 / 14(42.8)$ & $10 / 17(58.8)$ & $P=0.897$ & $-0.606-0.406$ \\
\hline Apgar $5^{\prime}(\mathrm{SD})$ & $4.8( \pm 2.0)$ & $4.1( \pm 2.1)$ & $P=0.419$ & $-0.334-1.607$ \\
\hline Umbilical cord pH (SD) & $6.881( \pm 0.1)$ & $6.996( \pm 0.2)$ & $P=0.066$ & $-0.397-0.079$ \\
\hline Umbilical cord $\mathrm{paCO}_{2}(\mathrm{mmHg})(\mathrm{SD})$ & $90.2( \pm 34.0)$ & $68.3( \pm 32.4)$ & $P=0.080$ & $-2.730-46.423$ \\
\hline Umbilical cord BE (mmol/L) (SD) & $-17.0( \pm 4.1)$ & $-17.7( \pm 7.1)$ & $P=0.981$ & $-2.592-7.207$ \\
\hline Umbilical cord lactate (mmol/L) (SD) & $12.1( \pm 6.3)$ & $14.1( \pm 4.6)$ & $P=0.378$ & $-6.694-2.632$ \\
\hline Onset of hypothermia h (SD) & $3.2( \pm 1.5)$ & $3.3( \pm 1.2)$ & $P=0.957$ & $-0.697-0.528$ \\
\hline Length of hospitalization (days) (SD) & $16.7( \pm 12.9)$ & $13.1( \pm 7.2)$ & $P=0.270$ & $-0.201-9.171$ \\
\hline
\end{tabular}

DH: deep hypothermia. MH: mild hypothermia. SD: standard deviation. BE: basic excess. h: hours.

pressure was $66 \mathrm{mmHg}$ and mean diastolic blood pressure was $41 \mathrm{mmHg}$, during $\mathrm{DH}$. During $\mathrm{MH}$, mean systolic blood pressure was $72 \mathrm{mmHg}$, and mean diastolic blood pressure was $46 \mathrm{mmHg}$ (Figure 3). Blood pressure was significantly lower in $\mathrm{DH}$ than $\mathrm{MH}$, and $\mathrm{DH}$ group presented a greater decrease in MAP during rewarming compared with $\mathrm{MH}$ with several statistical significance. Two newborns in $\mathrm{MH}$ and one in DH died, and that occurred 72 hours after hypothermia. Length of hospitalisation was similar in both groups (Table 1).

\section{Discussion}

Cardiovascular changes during cooling have a significant incidence on systemic sequelae in infants with HIE. The experimental data have shown that during mild hypothermia, left ventricular contractility and cardiac output decreased [21-23]. This is the first report that compares the cardiovascular function in treated asphyctic newborns with two different degrees of hypothermia. This report has demonstrated how the MAP changed during DH while HR remained the same changing degrees of cooling. In both treatment groups, target temperature was reached and maintained. Cooling was the same even using two different devices, and statistical difference was significant during hypothermia (Figure 1). Indeed, Hoedemaekers et al. showed that the use of different blankets did not change the induction and maintenance of cooling [24].

Thoresen and Whitelaw have documented how HR and MAP changed in asphyxiated newborns during hypothermia and rewarming. In fact, while the MAP increased, HR decreased during the cooling, and the opposite occurred during the rewarming [25]. Already three randomized controlled trials have been reported as a decrease in HR was reversible $[3,4,13]$. In the same way, it was already described

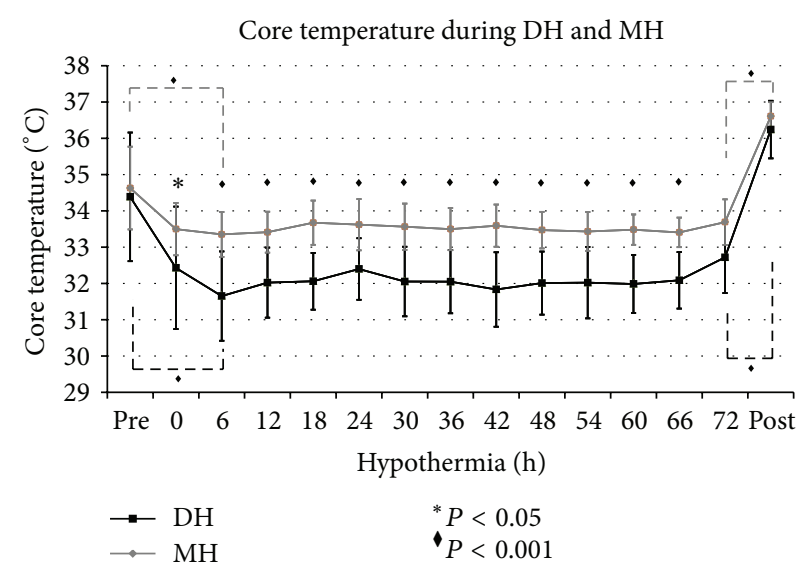

FIGURE 1: Core temperature during $\mathrm{DH}$ and $\mathrm{MH}$ (mean; standard deviation). The black and grey solid lines represent the core temperature during $\mathrm{DH}$ and $\mathrm{MH}$. The black asterisk $(*)$ represents the statistical significance with $P<0.05$. The black diamond ( $)$ represents the statistical significance with $P<0.001$. Core temperatures were the same between the two groups at starting hypothermic time; then the mean core temperature was $31^{\circ} \mathrm{C}$ and $33.5^{\circ} \mathrm{C}$ in $\mathrm{DH}$ and $\mathrm{MH}$, respectively. $\mathrm{DH}$ and $\mathrm{MH}$ had an analogous trend during cooling and rewarming. There was a statistical significant difference $(P<0.001)$, from 6 to 72 hours, between the two trends during cooling. There was statistical significance between prehypothermic and hypothermic temperature and hypothermic and postrewarming temperature $(P<0.001)$.

as neonates undergoing hypothermia were also exposed to sinus bradycardia and hypotension [7, 12, 26]. Furthermore, QTc elongation is a typical anomaly during hypothermia. Gunn et al. reported that HR of infants submitted to head cooling decreased and, at the same time, increased the QT interval. After rewarming, HR and QT interval came back to normal range $[20,27-30]$. 


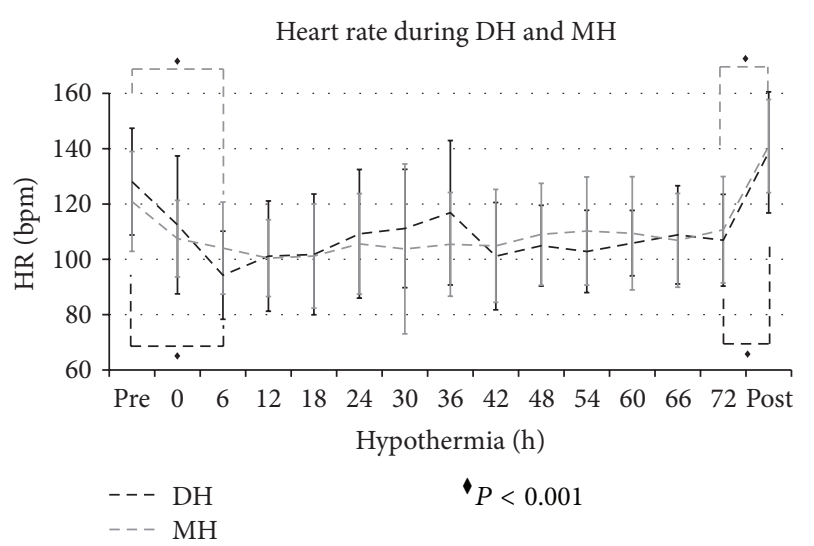

Figure 2: Heart rate during DH and MH (mean; standard deviation). The black dashed line represents the heart rate (HR) of newborns in deep hypothermia (DH). The grey dashed line represents the HR of newborns in mild hypothermia $(\mathrm{MH})$. The black diamond $(\checkmark)$ represents the statistical significance with $P<0.001$. HR was very comparable between the two groups at starting hypothermic time and during hypothermia. There was statistical significance between prehypothermic and hypothermic HR and hypothermic and postrewarming $\operatorname{HR}(P<0.001)$.

In this report, HR rapidly decreased during cooling induction and quickly increased during passive rewarming. Sinus bradycardia has been observed in both groups, while a significant increase in QTc developed only in 5 patients. The depth of hypothermia did not appear to affect HR while the induction of cooling and the gradual warming seemed to affect it (Figure 3).

Studies on pressure data are contradictory, because some have reported a pressure decrease, while others have documented an increase in blood pressure during hypothermia $[7,25]$.

In this report, blood pressures inevitably fall after the beginning of hypothermia in both groups and more in that subjected on deep hypothermia (Figure 3). However, a further decrease in blood pressure had been observed during rewarming only in DH group, as described by Thoresen and Whitelaw [25]. Although the rewarming rate was similar in both groups $\left(0.5^{\circ} \mathrm{C} / \mathrm{h}\right)$, we assumed that this rate was too elevated for those patients undergoing a more deep cooling. Therefore, based on previous studies, it is to suggest that there may be some benefit to give volume at the time of rewarming to "prime" the circulation [31].

Blood pressure significantly lower in the $\mathrm{DH}$ may be explained with inhibition of endogenous catecholamines activity following the further reduction on body temperature below $33^{\circ} \mathrm{C}$. Indeed, Chernow et al. measured HR, MAP, and plasma levels of catecholamines during progressive hypothermia to $29^{\circ} \mathrm{C}$ and then during rewarming to $37^{\circ} \mathrm{C}$ on baboon. HR, MAP, and plasma levels of epinephrine and norepinephrine increased significantly when the temperature dropped to $33^{\circ} \mathrm{C}$. A further reduction in temperature to $29^{\circ} \mathrm{C}$ corresponded with a reduction in HR, MAP, and catecholamine to prehypothermic levels. Therefore, sympathetic nervous system immediately responds to hypothermia but

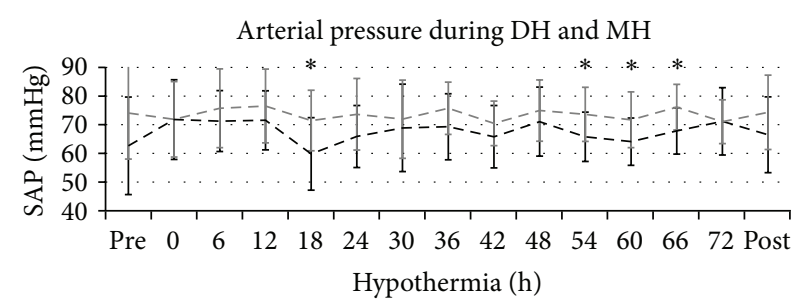

(a)

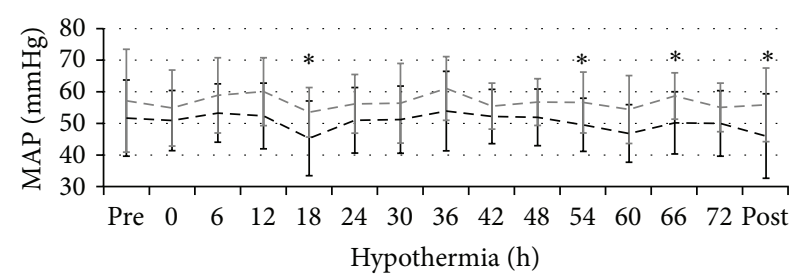

(b)

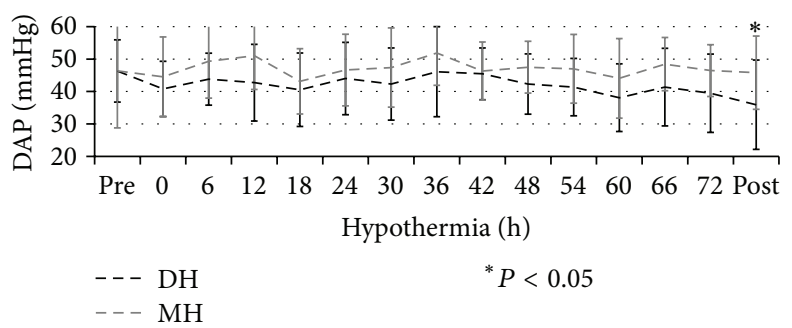

(c)

FIgURE 3: Change in arterial pressure during $\mathrm{DH}$ and $\mathrm{MH}$ (mean; standard deviation). The systolic (SAP), mean (MAP), and diastolic arterial pressure (DAP) was represented with black and grey dashed lines in patients during deep hypothermia (DH) and mild hypothermia $(\mathrm{MH})$, respectively. The black asterisk $(*)$ represents the statistical significance with $P<0.05$.

may be "switched off" at threshold temperature of about $29^{\circ} \mathrm{C}$ [32].

We also speculated that hypotension was probably also due to hypoxic multiorgan or multisystemic dysfunction (MOD) [33]. It is necessary to remember that MOD as renal, cardiovascular, pulmonary, or hepatic involvement is frequent in postasphyxial infants and is, respectively, present in $70 \%, 62 \%, 86 \%$, and $85 \%$ of infants with HIE [33].

The adverse effects of deep cooling may be more severe in asphyxiated newborns with multiorgan dysfunction, or multiorgan dysfunction could be amplified by superimposed cold-injury syndrome $[34,35]$. In an experimental adult dog model, deep hypothermia $\left(15^{\circ} \mathrm{C}\right)$ produced worse cerebral and cardiac outcomes [36], whereas controlled mild hypothermia $\left(34-36^{\circ} \mathrm{C}\right)$ provided consistent neuroprotective benefits [37]. The mechanisms of adverse effect of deep hypothermia or "overcooling" on cerebral outcome are not clear but might be related to myocardial dysfunction leading to decrease in cardiac output, systemic hypotension, and compromised cerebral perfusion [22, 36, 38, 39]. Deep hypothermia used in this study did not seem to be as profound as that used on the dogs by Dudgeon et al. [22], but it could itself be responsible to hypotension. 


\section{Conclusion}

In conclusion, the present report confirms that patients under $\mathrm{DH}$ are also subjected to cardiovascular dysfunction. Indeed, $\mathrm{DH}$ patients are subject to an increased risk of hypotension both during and after hypothermia. Small sample size, retrospective data collection, BP recording method, and observational clinical markers of cardiovascular status limit the power of our conclusions. However, deep hypothermia is safe and feasible treatment only if performed by a well-trained team [16, 17]. While moderate hypothermia can now be considered a "standard care" in asphyxiated term infants, $\mathrm{DH}$ should only be associated to a clinical trial. New prospective randomized trials are needed to validate its use.

\section{Ethical Approval}

The study protocol was approved by the Medical Ethical Committee of the "Carlo Poma" Hospital, Mantova, and the “A. Meyer” University Children's Hospital, Florence, Italy.

\section{Consent}

A parental consent was obtained.

\section{Disclosure}

This paper is not commissioned, externally peer reviewed.

\section{Conflict of Interests}

None of the authors has any conflict of interests to disclose.

\section{References}

[1] J. J. Kurinczuk, M. White-Koning, and N. Badawi, "Epidemiology of neonatal encephalopathy and hypoxic-ischaemic encephalopathy," Early Human Development, vol. 86, no. 6, pp. 329-338, 2010.

[2] J. M. Perlman, "Summary proceedings from the neurology group on hypoxic-ischemic encephalopathy," Pediatrics, vol. 117, no. 3, pp. S28-S33, 2006.

[3] P. D. Gluckman, J. S. Wyatt, D. Azzopardi et al., "Selective head cooling with mild systemic hypothermia after neonatal encephalopathy: multicentre randomised trial," The Lancet, vol. 365, no. 9460, pp. 663-670, 2005.

[4] S. Shankaran, A. R. Laptook, R. A. Ehrenkranz et al., "Whole-body hypothermia for neonates with hypoxic-ischemic encephalopathy," New England Journal of Medicine, vol. 353, no. 15, pp. 1574-1584, 2005.

[5] D. V. Azzopardi, B. Strohm, A. D. Edwards et al., "Moderate hypothermia to treat perinatal asphyxial encephalopathy," New England Journal of Medicine, vol. 361, no. 14, pp. 1349-1358, 2009.

[6] W. M. Parkins, J. M. Jensen, and H. M. Vars, "Brain cooling in the prevention of brain damage during periods of circulatory occlusion in dogs," Annals of Surgery, vol. 140, no. 3, pp. 284$289,1954$.
[7] S. Jacobs, R. Hunt, W. Tarnow-Mordi, T. Inder, and P. Davis, "Cooling for newborns with hypoxic ischaemic encephalopathy," Cochrane Database of Systematic Reviews, no. 4, p. CD003311, 2007.

[8] P. S. Shah, "Hypothermia: a systematic review and meta-analysis of clinical trials," Seminars in Fetal and Neonatal Medicine, vol. 15, no. 5, pp. 238-246, 2010.

[9] A. D. Edwards, P. Brocklehurst, A. J. Gunn et al., "Neurological outcomes at 18 months of age after moderate hypothermia for perinatal hypoxic ischaemic encephalopathy: synthesis and meta-analysis of trial data," British Medical Journal, vol. 340, p. c363, 2010 .

[10] R. E. Hoesch and R. G. Geocadin, "Therapeutic hypothermia for global and focal ischemic brain injury-a cool way to improve neurologic outcomes," Neurologist, vol. 13, no. 6, pp. 331-342, 2007.

[11] K. H. Polderman, "Application of therapeutic hypothermia in the ICU: opportunities and pitfalls of a promising treatment modality. Part 1: indications and evidence," Intensive Care Medicine, vol. 30, no. 4, pp. 556-575, 2004.

[12] K. H. Polderman, "Application of therapeutic hypothermia in the intensive care unit: opportunities and pitfalls of a promising treatment modality. Part 2: practical aspects and side effects," Intensive Care Medicine, vol. 30, no. 5, pp. 757-769, 2004.

[13] D. J. Eicher, C. L. Wagner, L. P. Katikaneni et al., "Moderate hypothermia in neonatal encephalopathy: efficacy outcomes," Pediatric Neurology, vol. 32, no. 1, pp. 11-17, 2005.

[14] S. Shankaran, A. Laptook, L. L. Wright et al., "Whole-body hypothermia for neonatal encephalopathy: animal observations as a basis for a randomized, controlled pilot study in term infants," Pediatrics, vol. 110, no. 2, pp. 377-385, 2002.

[15] A. J. Gunn and M. Battin, "Hypothermic centralization: new use for old knowledge?” Pediatrics, vol. 106, no. 1, pp. 133-134, 2000.

[16] G. Compagnoni, C. Bottura, G. Cavallaro, G. Cristofori, G. Lista, and F. Mosca, "Safety of deep hypothermia in treating neonatal asphyxia," Neonatology, vol. 93, no. 4, pp. 230-235, 2008.

[17] G. Cavallaro, L. Filippi, G. Cristofori et al., "Does pulmonary function change during whole-body deep hypothermia?" Archives of Disease in Childhood, vol. 96, no. 5, pp. F374F377, 2011.

[18] L. Filippi, G. La Marca, P. Fiorini et al., "Topiramate concentrations in neonates treated with prolonged whole body hypothermia for hypoxic ischemic encephalopathy," Epilepsia, vol. 50, no. 11, pp. 2355-2361, 2009.

[19] L. Filippi, C. Poggi, G. La Marca et al., "Oral topiramate in neonates with hypoxic ischemic encephalopathy treated with hypothermia: a safety study," Journal of Pediatrics, vol. 157, no. 3, pp. 361-366, 2010.

[20] M. J. Ree, "Electrocardiographic changes in accidental hypothermia," British Heart Journal, vol. 26, pp. 566-571, 1964.

[21] J. M. Perlman, "Systemic abnormalities in term infants following perinatal asphyxia: relevance to long-term neurologic outcome," Clinics in Perinatology, vol. 16, no. 2, pp. 475-484, 1989.

[22] D. L. Dudgeon, P. A. Randall, and J. G. McAfee, "Mild hypothermia: its effect on cardiac output and regional perfusion in the neonatal piglet," Journal of Pediatric Surgery, vol. 15, no. 6, pp. 805-810, 1980.

[23] P. S. Greene, D. E. Cameron, M. L. Mohlala, J. M. Dinatale, and T. J. Gardner, "Systolic and diastolic left ventricular dysfunction 
due to mild hypothermia," Circulation, vol. 80, no. 5, pp. 44-48, 1989.

[24] C. W. Hoedemaekers, M. Ezzahti, A. Gerritsen, and J. G. van der Hoeven, "Comparison of cooling methods to induce and maintain normo- and hypothermia in intensive care unit patients: a prospective intervention study," Critical Care, vol. 11, p. R91, 2007.

[25] M. Thoresen and A. Whitelaw, "Cardiovascular changes during mild therapeutic hypothermia and rewarming in infants with hypoxic-ischemic encephalopathy," Pediatrics, vol. 106, no. 1, pp. 92-99, 2000.

[26] R. E. Lasky, N. A. Parikh, A. L. Williams, N. S. Padhye, and S. Shankaran, "Changes in the PQRST intervals and heart rate variability associated with rewarming in two newborns undergoing hypothermia therapy," Neonatology, vol. 96, no. 2, pp. 93-95, 2009.

[27] T. R. Gunn, N. J. Wilson, S. Aftimos, and A. J. Gunn, "Brain hypothermia and QT interval,” Pediatrics, vol. 103, no. 5, p. 1079, 1999.

[28] R. Thompson, J. Rich, F. Chmelik, and W. Nelson, "Evolutionary changes in the electrocardiogram of severe progressive hypothermia," Journal of Electrocardiology, vol. 10, no. 1, pp. 67$70,1977$.

[29] M. Okada, "The cardiac rhythm in accidental hypothermia," Journal of Electrocardiology, vol. 17, no. 2, pp. 123-128, 1984.

[30] D. Emslie-Smith, "Changes in the electrocardiogram during preoperative hypothermia in man," Australasian annals of medicine, vol. 5, no. 1, pp. 62-67, 1956.

[31] M. R. Battin, M. Thoresen, E. Robinson, R. A. Polin, A. D. Edwards, and A. J. Gunn, "Does head cooling with mild systemic hypothermia affect requirement for blood pressure support?” Pediatrics, vol. 123, no. 3, pp. 1031-1036, 2009.

[32] B. Chernow, C. R. Lake, and A. Zaritsky, "Sympathetic nervous system "switch off" with severe hypothermia," Critical Care Medicine, vol. 11, no. 9, pp. 677-680, 1983.

[33] P. Shah, S. Riphagen, J. Beyene, and M. Perlman, "Multiorgan dysfunction in infants with post-asphyxial hypoxic-ischaemic encephalopathy," Archives of Disease in Childhood, vol. 89, no. 2, pp. F152-F155, 2004.

[34] P. B. Tsivyan and A. D. Vasenina, "Left ventricular systolic and diastolic function in term neonates after mild perinatal asphyxia," European Journal of Obstetrics Gynecology and Reproductive Biology, vol. 40, no. 2, pp. 105-110, 1991.

[35] V. Weinrauch, P. Safar, S. Tisherman, K. Kuboyama, A. Radovsky, and R. C. Koehler, "Beneficial effect of mild hypothermia and detrimental effect of deep hypothermia after cardiac arrest in dogs," Stroke, vol. 23, no. 10, pp. 1454-1462, 1992.

[36] R. A. Primhak, R. Jedeikin, and G. Ellis, "Myocardial ischaemia in aphyxia neonatorum. Electrocardiographic, enzymatic and histological correlations," Acta Paediatrica Scandinavica, vol. 74, no. 4, pp. 595-600, 1985.

[37] P. Safar, F. Xiao, A. Radovsky et al., "Improved cerebral resuscitation from cardiac arrest in dogs with mild hypothermia plus blood flow promotion," Stroke, vol. 27, no. 1, pp. 105-113, 1996.

[38] C. M. Gebauer, M. Knuepfer, E. Robel-Tillig, F. Pulzer, and C. Vogtmann, "Hemodynamics among neonates with hypoxicischemic encephalopathy during whole-body hypothermia and passive rewarming," Pediatrics, vol. 117, no. 3, pp. 843-850, 2006.

[39] S. Sarkar and J. D. Barks, "Systemic complications and hypothermia," Seminars in Fetal and Neonatal Medicine, vol. 15, no. 5, pp. 270-275, 2010. 


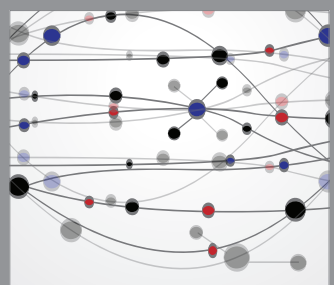

The Scientific World Journal
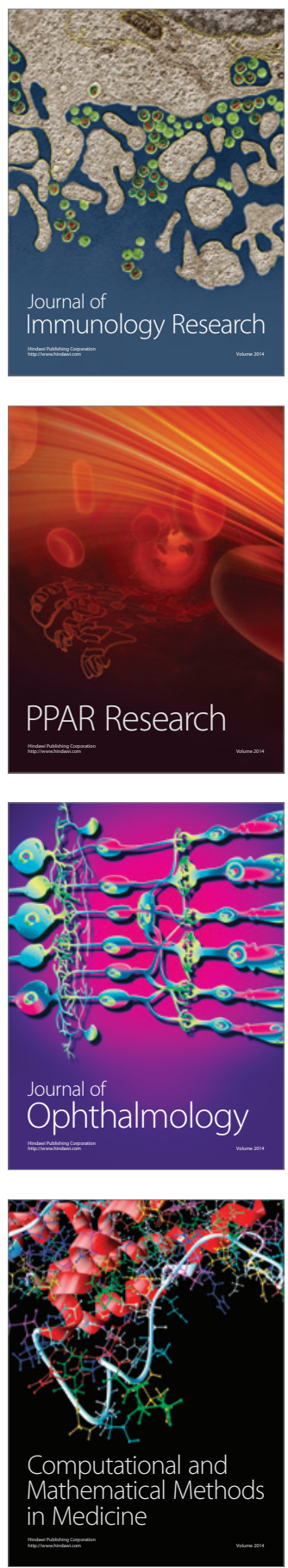

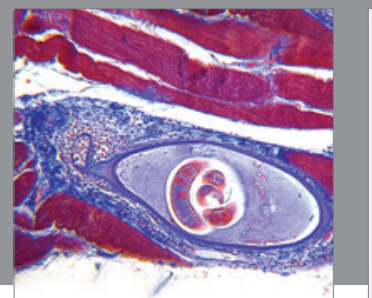

Gastroenterology

Research and Practice
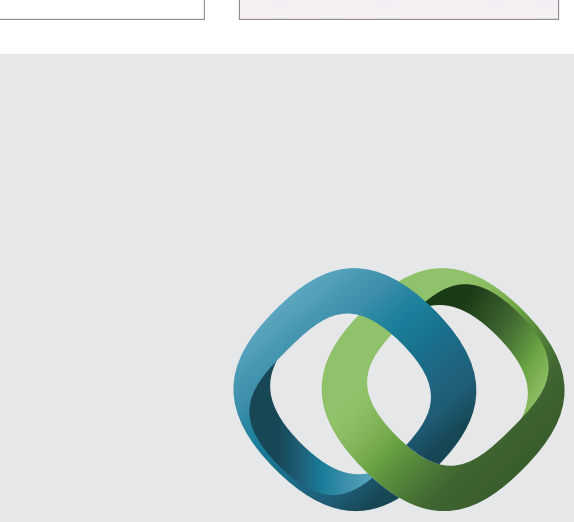

\section{Hindawi}

Submit your manuscripts at

http://www.hindawi.com
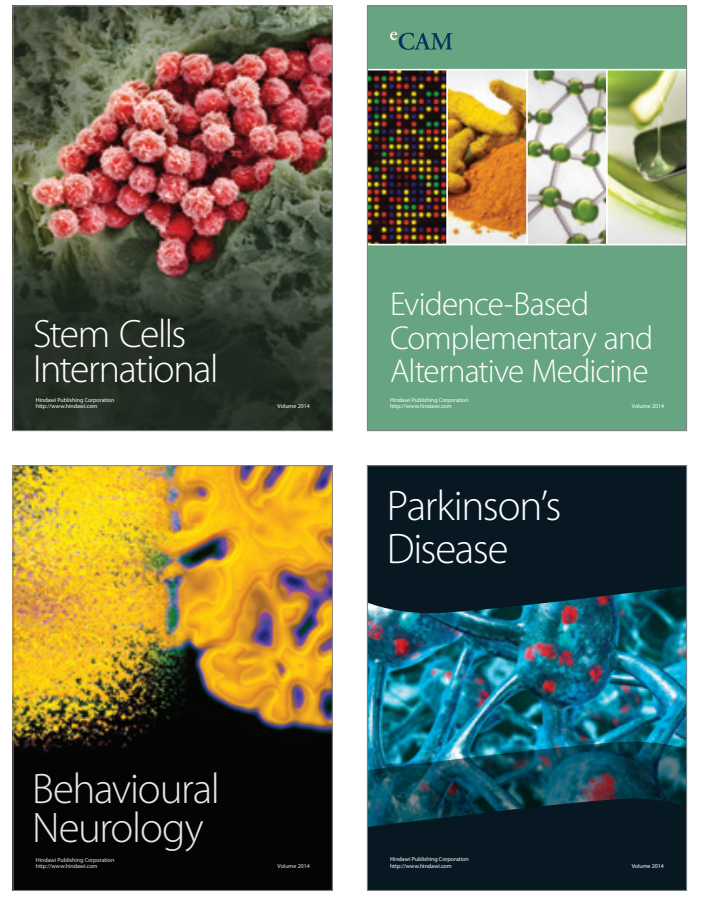
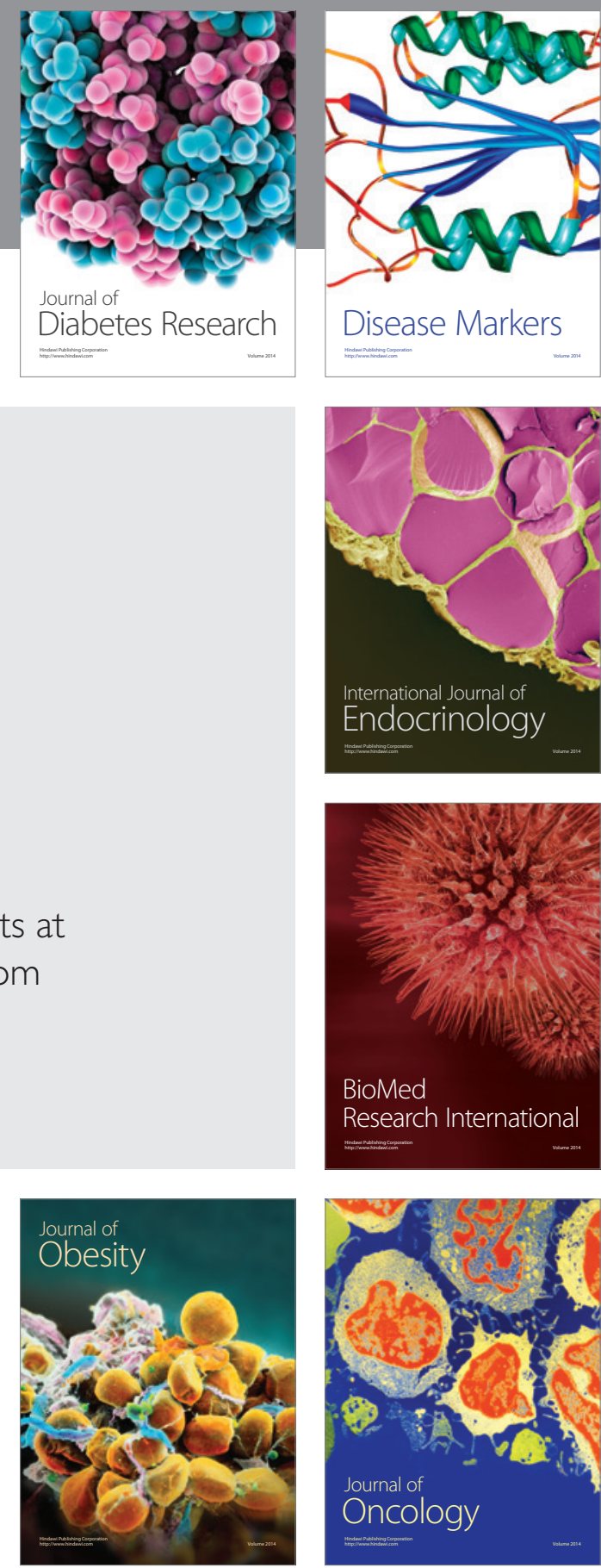

Disease Markers
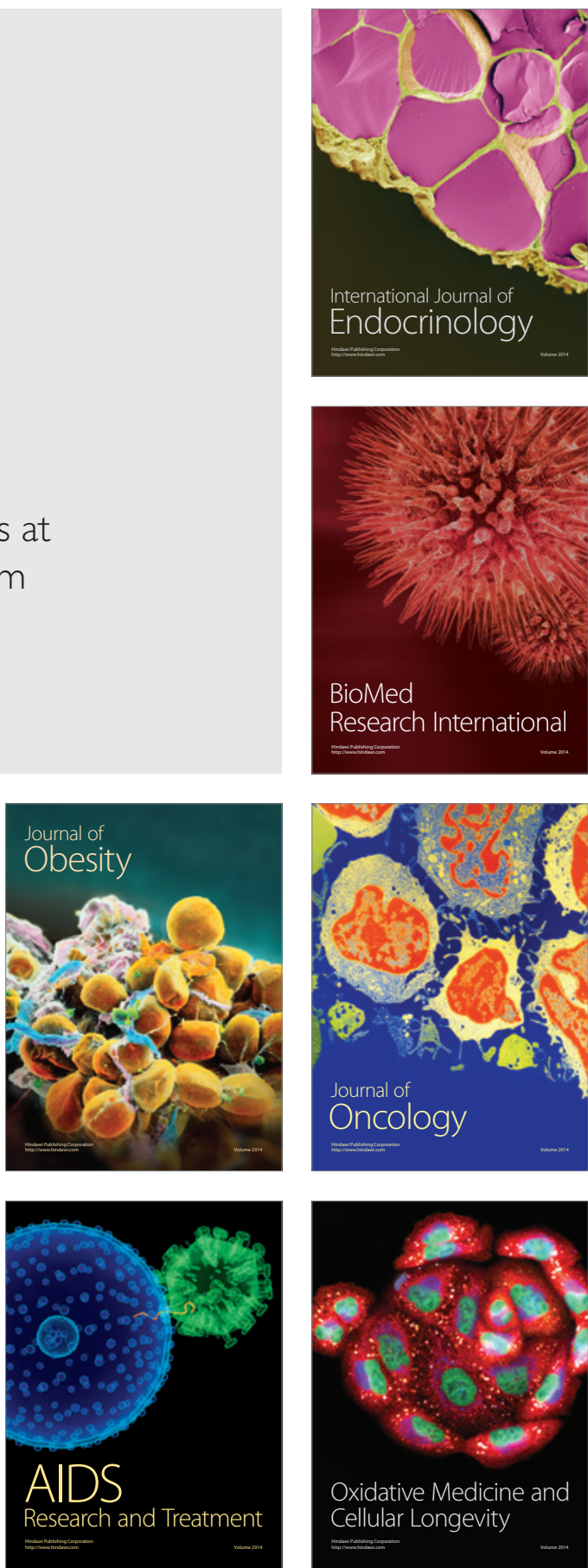